\title{
A Unique Step towards Generation of Electricity via New Methodology
}

\author{
Itika Tandon ${ }^{1}$, Alok Kumar ${ }^{2}$ \\ Graduate Scholar, Dept. of ECE, CT Institute of Technology, Jalandhar, Punjab, India ${ }^{1}$
}

Research Assistant, Dept. of ECE, CT Institute of Engineering, Management and Technology, Jalandhar, Punjab, India ${ }^{2}$

\begin{abstract}
In this paper we are representing the methodology of electrical power generation using human footstep. This is about how we can generate electricity using human's waste foot energy and applications for the same. When human walk in surroundings some force exerts on surface this force can be used to generate electricity. The idea of convertingpressurize weight energy into the electrical energy is possible by piezo-electric crystal. The power generating floors can be a major application if we use piezoelectric crystals as an energy converting material. The piezo-electric crystals have crystalline structure and ability to convert the mechanical energy (stress and strain) into the electrical energy. Whenever there is some vibrations, stress or straining force is exert by foot onfloorthen these crystals evenlyconverts it into electric power which can be used for charging devices viz laptop, mobiles, electronic devices etc. In this paper, we are discussed about applications and generation of electricity in the area of power harvesting.
\end{abstract}

KEYWORDS: Piezoelectric material, Piezo-electric crystals, Energy generation, Power Harvesting.

\section{INTRODUCTION}

Now days, electricity has become a need of every single human, demand of electricity increasing day by day.This new generation needs lots of electrical power for their different operations. Due to this many sources are wasted and exhausted in a large amount.There are various ways to generate electricity. The human bio-energy being wasted if it can be made possible for utilization it will be very useful energy sources [1]. The human waste foot energy is being use to produce electricity this would be a great evolution in electricity generation. The average human can take 3,000 -5,000 steps a day [2]. When we walk then some of energy is wasted in the form of vibrations we can convert this energy or vibrations into an electrical energy using piezo-electric crystals. The use of piezo-electric crystal is to produce the electric output from surrounding vibrations. These materials have the ability to absorb mechanical energy from their surroundings, usually ambient vibration and transform it into electrical energy that can be used to power other devices. Piezoelectricity refers to the ability of some materials to generate an electric potential in response to applied pressure[1-3] Embedded piezo-electric crystals provide the ability to convert the human walking energy into the electric current due to the exerted pressure.

This paper comprises of four section namely study of piezoelectric material, application of energy harvesting via piezoelectric material, locations for generating large scale electricityand conclusion.

\section{II.STUDY OF PIEZOELECTRIC MATERIAL}

Piezoelectric crystals are the energy sources. The piezoelectric crystals produce the voltage which can be use for power many things. The piezoelectric crystals have a crystalline structure which converts an applied vibration into an electrical energy.

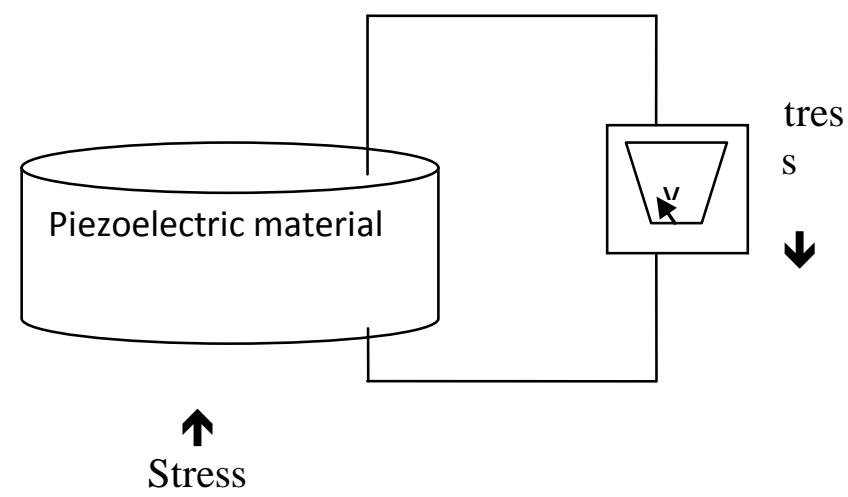

Fig.1 Diagram of Piezoelectric Effect

The piezoelectric effect exists in two properties first the piezoelectric effect is a reversible process in that materials exhibiting the direct piezoelectric effect (the internal generation of electrical charge resulting from an applied mechanical force) second it also exhibit the reverse piezoelectric effect (the internal generation of a mechanical strain resulting from an applied electrical field) this is the best way of power harvesting [4].

\section{III.APPLICATIONS OF ENERGY HARVESTING VIA PIEZOELECTRIC MATERIAL}

\section{A Flooring Tiles}

The flooring tiles are made up of rubber which can absorb the vibration and under these the piezoelectric materials are placed so as when the movement is felt by the material they can generate the electricity. When these kind of tiles are installed in locations where large crowd movements are expected such as in Railway station ,Bus stations, Airports, Malls, footpaths etc, and when a person steps on them, then by piezoelectric effect small charge is built up. So the energy generated by one human would be too less but if number of steps on these kind of tiles increase then 
energy produced by it would increase too. When a person steps on such tiles piezoelectric crystal under the tiles would experience some mechanical stress which makes electric charge to built up on crystal's surface which can be collected by use of electrodes. This kind of energy can be stored in capacitors and power can be transfer to energy deficient regions. Japan has already started experimenting use of piezoelectric effect for energy generation by installing special flooring tiles at its capitals' two busiest stations. Tiles are installed in front of ticket turnstiles. Thus every time a passenger steps on mats, they trigger a small vibration that can be stored as energy [5].

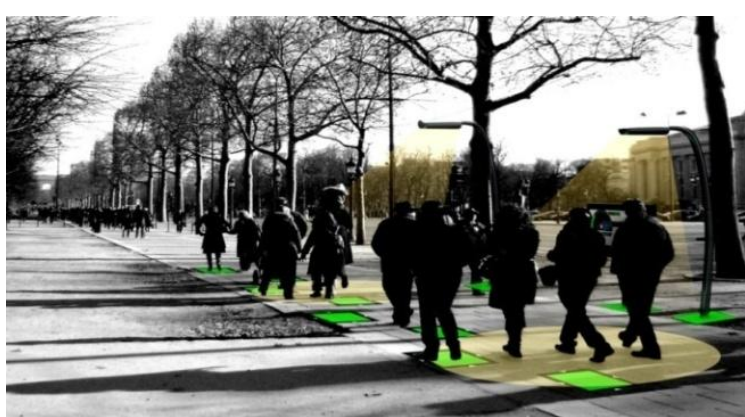

Fig 2. Special flooring of tiles using piezoelectric material

\section{B. Road side to Power street lights}

The present invention relates generally to methods of electrical power generation and more particularly is a method and device to generate electricity by using traffic on existing roadways to drive an electrical generator[6]. The idea of constructing the special types of roads which generate the electricity is a unique application in power harvesting methodology. This system works by embedding tiny piezoelectric crystals into the road.

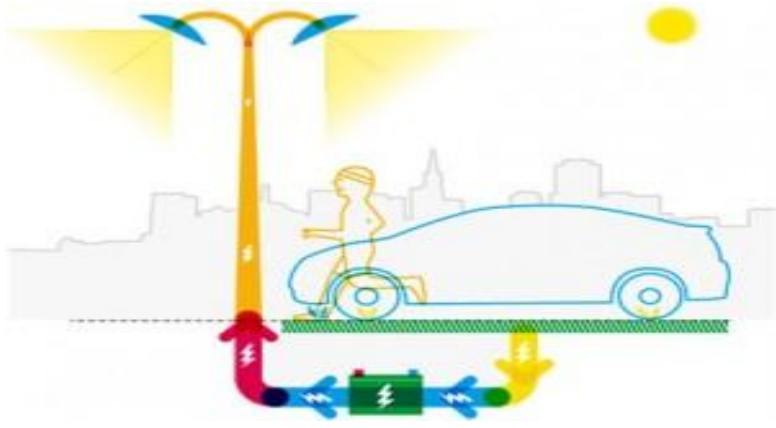

Fig 3. Specially designed road forpower harvesting

When automobiles or vehicles drive over through this road then the piezoelectric crystals sense the force and pressure which generates the small electrical charge. Though small charge is generated by single car but $1 \mathrm{~km}$ stretch of such road could generate around $400 \mathrm{~kW}$-enough to run eight small cars. Such experimenting have already started in Israel [5].

\section{Dance Floors}

Apart from roads and railway stations, piezoelectric effect is also being in use in the dance floors. In Europe, certain nightclubs have already begun to power their night clubs, strobes and stereos by use of piezoelectric crystals
[7].These floors are using the piezoelectric effect. As the floor is compressed by the dancers feet the piezoelectric material makes contact and generate the electricity around 2-20 watts. It depends on the impact of the feet. The constant compression of piezoelectric crystals causes a huge amount of energy to be generated, which can comfortably drive the remotely placed low power consuming devices [8].

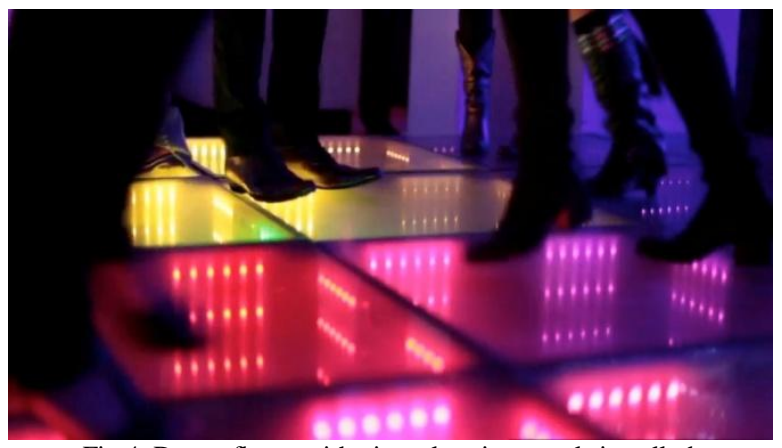

Fig 4. Dance floors with piezoelectric crystals installed

\subsection{Inside the Footwear heel}

Apart from tiles, roads, dance floors, attempts are made to harvest energy from our daily movements by installing piezoelectric crystals in the shoes also. These shoes would have piezoelectric crystals at the rear end or near heel. Thus with each step piezoelectric crystal would go through pressure and force which in turn can generate enough energy to power cell phones, mp3 players etc. If these such shoes undergo through movements daily then these will be able to generate electricity enough to charge up the small electronic devices or gadgets. Often we can do that with a piezoelectric transducer, a transducer is simply a device that converts small amount of energy from one kind to another for instance converting light, sound or mechanical pressure into electrical signals[9].

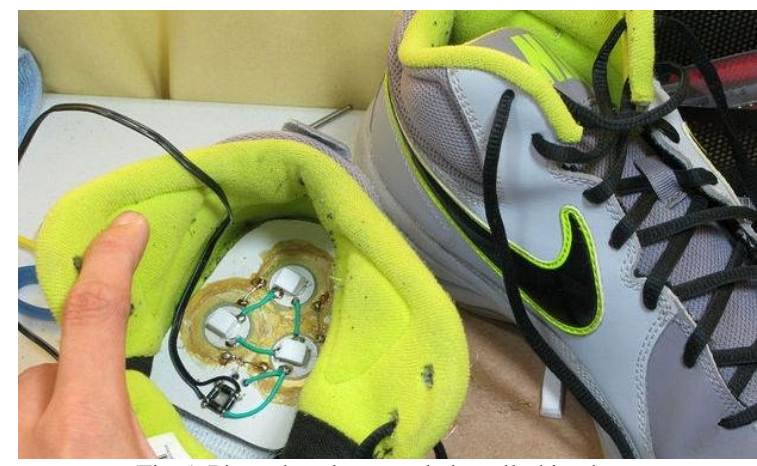

Fig 5. Piezoelectric crystals installed in shoe

\section{LOCATIONS FOR GNERATING LARGE SCLAE ELECTRICITY}

\section{A. Roads and Highways}

The traffic is more in day than the night and sometimes traffic run 24 hrsand the traffic varies throughout the day. The total force exerted by moving automobiles on the road surface can be calculated by considering the average number of vehicles passing through certain point, for a certain time period. In a survey Israel is putting PEG $6 \mathrm{~cm}$ under the road level and at a distance of $30 \mathrm{~cm}$ apart. From 
this trial, it has been seen that a vehicle weighing at being started in many countries viz Japan, Israel, around 5 tons can generate $2000 \mathrm{~V}$, and a $1 \mathrm{Km}$ cluster of Netherlands. Use of piezo-electric material is eco-friendly such generator can generate $400 \mathrm{Kwh}$ energy. If 600 causes no pollution. It is an inexpensive way of generating vehicles are allowed to go through this road for an hour, it electricity and is easy to install. In future this method will can power up to $600-800$ homes [10].

\section{B. Power Generating from Footpaths} be a promising method for generating eco-friendly electricity. We also contribute this method at common places like home entrance gates, parking area, bus stands

Footpath is most common place on where we embed the piezoelectric tiles to produce the small amount of energy by utilizing the human footstep over it. The produced charge is stored in battery and then that stored charge can be use for charging low power electronic devices.

\section{Power Generating Railway Tracks}

The railway tracks are the important place which is responsible for generation of large energy as the huge amount of pressure is exerted by trains on the railway tracks. The embedded piezoelectric crystals at the railway tracks where wheels make contact with the tracks and these materials get excessive pressure and force, because of this greater amount of energy is stored.

\section{Power Generating Airport Runway}

In large amount of pressure is exerted on runways, when the aircraft takes off or lands. If we place the piezoelectric clusters here then we can convert this mechanical energy. The efficiency of system can be improved by placing the stacked structure which is consist of several layers of piezoelectric clusters and have the capacity to handle the huge amount of pressure.. The maximum takeoff weight for the airbus aircraft (A380) is 560 tones, which can produce $224 \mathrm{KV}$, so if one considers the total number of landing in the runway a large amount of energy could be produced. Nearly $8138 \mathrm{kWh}$ energy could be produced which can power up to $12207-16276$ homes [10].

\section{E. Schools, Colleges, Shopping Malls and Gyms}

Having the flooring of piezoelectric material will cause to produce the more energy in the malls and schools. We can embed the piezoelectric tiles at the entrance of the malls and schools. The idea of utilizing the vibrations caused by the machines in the gym and at workplaces also while sitting on the chair, this energy can be stored in the batteries by putting the piezoelectric crystals in the chair.

\section{F. Schools, Colleges, Shopping Malls and Gyms}

Having the flooring of piezoelectric material will cause to produce the more energy in the malls and schools. We can embed the piezoelectric tiles at the entrance of the malls and schools. The idea of utilizing the vibrations caused by the machines in the gym and at workplaces also while sitting on the chair, this energy can be stored in the batteries by putting the piezoelectric crystals in the chair.

\section{CONCLUSION}

This statement of Albert Einstein is true "Energy can neither be created nor be destroyed it can be transferred from one form to another." This method of generating electricity by the use of piezoelectric material has already

etc. This method will exploits different areas of electricity generation.

\section{REFERENCES}

[1]. Prabaharan ,Jayaramaprakash , Vijay Anand,“ Power harvesting by using human footstep "International Journal of Innovative Research in Science, Engineering and Technology, Vol. 2, Issue 7, July 2013.

[2]. Monika jain, MohitDev Sharma, NitiRana, Nitish Gupta, "VIDYUT Generation via Walking : Analysis", International journal of engineering sciences and research technology, Feb 2013.

[3]. KiranBoby, Aleena Paul K, Anumol.C.V, Josnie Ann Thomas, Nimisha K.K "Footstep Power Generation Using Piezo Electric Transducers"International Journal of Engineering and Innovative Technology (IJEIT), Vol 3, Issue 10, April 2014

[4]. MuktiNath Gupta, Suman and S.K.Yadav "Electricity Generation Due to Vibration of Moving Vehicles Using Piezoelectric Effect" Advance in Electronic and Electric Engineering, Vol4, Number3, 2014.

[5]. Pramathesh.T, Ankur.S "Piezoelectric Crystals : Future Source of Electricity" International Journal of Scientific Engineering and Technology Vol 2, Issue 4, 1april 2013.

[6]. Aqsa Abbasi,"Application of Piezoelectric Materials in Smart Roads and MEMS, PMPG Power Generation with Transverse Mode Thin Film PZT", International Journal of Electrical and Computer Engineering (IJECE) Vol. 3, No. 6, pp. 857 862, December 2013,

[7]. PratibhaArun V, Divyesh Mehta, "Eco-Friendly Electricity Generator Using Scintillating Piezo",International Journal of Engineering Research and Applications,Vol. 3, Issue 5, Sep-Oct 2013.

[8]. TanviDikshit, DhawalShrivastava, AbhijeetGorey, Ashish Gupta, ParagParandkarandSumantKatiyal"Energy Harvesting via Piezoelectricity".

[9]. Ms.KambleSushamaBaburao"Development of Energy Harvesting Source from Piezoelectric Shoe"Proc. of the Second Intl. Conf. on Advances in Computer, Electronics and Electrical Engineering CEEE 2013

[10]. Sandeep D. Mendhule , Vilas K.Kankal "Harvesting Electrical Energy from Footsteps"Vol. 1, Number 2, 2013 